\title{
The Effectiveness of a Structured Telephone Support Program for Rural Patients with Heart Failure
}

\author{
Debra J. Ansinelli \\ West Virginia University
}

Follow this and additional works at: https://researchrepository.wvu.edu/etd

\section{Recommended Citation}

Ansinelli, Debra J., "The Effectiveness of a Structured Telephone Support Program for Rural Patients with Heart Failure" (2013). Graduate Theses, Dissertations, and Problem Reports. 475.

https://researchrepository.wvu.edu/etd/475

This Dissertation is protected by copyright and/or related rights. It has been brought to you by the The Research Repository @ WVU with permission from the rights-holder(s). You are free to use this Dissertation in any way that is permitted by the copyright and related rights legislation that applies to your use. For other uses you must obtain permission from the rights-holder(s) directly, unless additional rights are indicated by a Creative Commons license in the record and/ or on the work itself. This Dissertation has been accepted for inclusion in WVU Graduate Theses, Dissertations, and Problem Reports collection by an authorized administrator of The Research Repository @ WVU.

For more information, please contact researchrepository@mail.wvu.edu. 
The Effectiveness of a Structured Telephone Support Program for

Rural Patients with Heart Failure

Debra J. Ansinelli

Doctoral Research Project submitted to the

School of Nursing

at West Virginia University

in partial fulfillment of the requirements

for the degree of

Doctor of Nursing Practice

Susan McCrone, PhD, Chair

Lisa Hardman, DNP

David Bush, MD

Department of Health Sciences

Morgantown, West Virginia

2013

Keywords: heart failure, readmission, telephone, telemonitoring, quality of life, anxiety 


\section{ABSTRACT \\ The Effectiveness of a Structured Telephone Support Program for Rural Patients with Heart Failure}

\section{Debra J. Ansinelli}

The health of a population is influenced by the physical, social, cultural, and economic environment. Limited access to care has been cited as a reason why the Appalachian region of Kentucky has one of the highest rates of cardiovascular disease in the developed world. Kentucky ranked seventh in the nation for heart failure (HF) death rates 2007-2009. The objectives of this project were to evaluate the effectiveness of a structured telephone support program for HF management to improve self-care behaviors and quality of life and to reduce anxiety, 30 day readmission rates, and mortality rates in rural patients with heart failure. A quasi experimental one group pretest, posttest design was used to determine the effectiveness of a structured telephone program. A convenience sample of thirty patients admitted to 3 hospitals in rural Kentucky with a diagnosis of heart failure participated in the program. Prior to discharge from the hospital, patients were asked to complete the Minnesota Living with Heart Failure Questionnaire (MLHFQ), the Self-care of Heart Failure Index (SCHFI), which consists of 3 sections (A, B, C) designed to measure self-care maintenance, management, and confidence, and the state anxiety (S-Anxiety) scale of the State-Trait Anxiety Inventory (STAI). Approximately 72 hours after discharge and weekly for 4 weeks, patients were called by the project coordinator. During these calls, an evidence based script was used as a guide to provide patient education and clinical advice. During the last call, the MLHFQ, the SCHFI, and the S-Anxiety were repeated. Paired samples t-testing was performed to evaluate the impact of the program on participant's MLHFQ, SCHFI, and S-Anxiety scores. There was a significant decrease in scores on the MLHFQ from the pretest $(M=48.23$, SD 8.74) to the posttest $(M=40.4667$, SD 9.878), $t(29)=$ $11.056, \mathrm{p}<.005$. There was a significant increase in SCHFI B scores from pretest $(\mathrm{M}=44.80$, $\mathrm{SD} 19.120)$ to posttest $(\mathrm{M}=55.40, \mathrm{SD} 15.540), \mathrm{t}(24)=5.338, \mathrm{p}<.005$. There was a significant increase in SCHEFI C scores from pretest $(M=57.077$, SD 19.022) to posttest $(\mathrm{M}=61.340, \mathrm{SD}$ $17.322), \mathrm{t}(29)=4.490, \mathrm{p}<.005$. While overall scores on the SCHFI improved, scores did not meet the cut off score of 70 to be considered adequate for self-care behavior. There was a significant decrease in S-Anxiety scores from pretest $(M=39.5667$, SD 9.073) to the posttest (M $=36.8333, \mathrm{SD} 8.469), \mathrm{t}(29)=5.634, \mathrm{p}<.005$. There was a significant increase in SCHEFI A scores from pretest $(\mathrm{M}=50.438, \mathrm{SD}=13.353)$ to posttest $(\mathrm{M}=59.661, \mathrm{SD}=12.993), \mathrm{t}(29)=$ $7.733, \mathrm{p}<.0005$. Seven study participants $(23 \%)$ were readmitted to the hospital within 30 days. The average facility 30 -day readmission rate for hospitals included in this study is $27.15 \%$. The national 30- day readmission rate for heart failure is $24.7 \%$. None of the study participants died during the study. The average 30-day mortality rate for hospitals included in the study is $6.6 \%$. The national 30 -day mortality rate for heart failure is $11.6 \%$. A structured telephone support program was effective in improving quality of life, self-care behaviors, and in reducing anxiety, 30-day readmissions, and mortality in patients with heart failure. Additional intervention is needed to insure adequate self-care behavior. 


\section{Executive Summary}

\section{Background}

Kentucky ranked seventh in the nation for HF death rates 2007-2009. The health of a population is influenced by the physical, social, cultural, and economic environment. Limited access to care has been cited as a reason why the Appalachian region of Kentucky has one of the highest rates of cardiovascular disease in the developed world.

\section{Objectives}

The objectives of this project were to evaluate the effect of a structured telephone program as an alternative approach to HF management geared towards improving quality of life and self-care behaviors, and in reducing anxiety, 30 day readmission rates, and mortality rates in rural patients with heart failure.

\section{Design}

A quasi experimental one group, pretest, posttest design was used to determine the effectiveness of a structured telephone program on self-care behaviors, health related quality of life, and anxiety in patients hospitalized with heart failure. The investigator served as the project coordinator. Recruitment was done during a patient's hospitalization with a diagnosis of heart failure. Prior to discharge from the hospital and after signing a consent form, participants were asked to complete the Minnesota Living with Heart Failure Questionnaire (MLHFQ), the SelfCare of Heart Failure Index (SCHFI) consisting of 3 sections (A, B, C) designed to measure selfcare maintenance, management, and confidence, and the state anxiety (S-Anxiety) scale of the State-Trait Anxiety Inventory (STAI). These instruments are designed to measure quality of life, self-care behavior, and anxiety. Approximately 72 hours after discharge and weekly for 4 weeks, patients were called by the project coordinator. During these calls, an evidence based script was 
used as a guide to provide patient education and clinical advice. During the last call, the MLHFQ, SCHFI, and the S-Anxiety were repeated.

\section{Subjects}

The one group convenience sample $(\mathrm{N}=30)$ consisted of 17 men and 13 women. The average age of study participants was 66.43 (range 48-85). Forty percent were married; $100 \%$ of the study participants were Caucasian; $57.6 \%$ of the study participants completed high school. One participant completed college. The average ejection fraction of the study participants was 44.53 (range 15\%-67\%). Thirty percent of the study participants had a diagnosis of anxiety; 20\% had a diagnosis of depression.

\section{Results}

A paired samples t-test was conducted to evaluate the impact of the intervention on participant's MLHFQ, SCHFI, and S-STAI scores. There was a significant decrease in scores on the MLHFQ from the pretest $(M=48.23, \mathrm{SD} 8.74)$ to the posttest $(M=40.4667, \mathrm{SD} 9.878), \mathrm{t}(29)=11.056, \mathrm{p}$ $<.005$ (one tailed). The mean decrease in MLHFQ scores was 7.767 with a 95\% confidence interval ranging from 6.330 to 9.203. There was a significant increase in SCHEFI A scores from pretest $(\mathrm{M}=50.438, \mathrm{SD}=13.353)$ to posttest $(\mathrm{M}=59.661, \mathrm{SD}=12.993), \mathrm{t}(29)=7.733, \mathrm{p}<$ .0005 (one-tailed). The mean increase in SCHFI A scores was 9.221 with a $95 \%$ confidence interval ranging from 6.782 to 11.660. There was a significant increase in SCHFI B scores from pretest $(M=44.80, \mathrm{SD} 19.120)$ to posttest $(\mathrm{M}=55.40, \mathrm{SD} 15.540), \mathrm{t}(24)=5.338, \mathrm{p}<.005$ (onetailed). The mean increase in SCHFI B scores was 10.600 with a $95 \%$ confidence interval ranging from 6.502 to 14.698 . There was a significant increase in SCHEFI C scores from pretest $(\mathrm{M}=57.077, \mathrm{SD} 19.022)$ to posttest $(\mathrm{M}=61.340, \mathrm{SD} 17.322), \mathrm{t}(29)=4.490, \mathrm{p}<.005$ (onetailed). The mean increase in SCHFI C scores was 4.262 with a 95\% confidence interval ranging 
from 2.321 to 6.204 . There was a significant decrease in S-Anxiety scores from pretest $(\mathrm{M}=$ 39.5667, SD 9.073) to posttest $(\mathrm{M}=36.8333$, $\mathrm{SD} 8.469), \mathrm{t}(29)=5.634, \mathrm{p}<.005$ (one tailed). The mean decrease in S-Anxiety scores was 2.733 with a $95 \%$ confidence interval ranging from 1.691 to 3.775 . Seven study participants $(\mathrm{N}=30)(23 \%)$ were readmitted to the hospital within 30 days over the course of the study. The average facility 30 -day readmission rate for hospitals included in this study is $27.15 \%$ based on 437 eligible admissions for this measure. The national 30- day readmission rate for heart failure is $24.7 \%$. None of the study participants $(\mathrm{N}=30)$ died during the study. The average 30-day mortality rate for hospitals included in the study is $6.6 \%$ based on 362 eligible admissions for this measure. The national 30-day mortality rate for heart failure is 11.6

\section{Conclusion}

Participants in the structured telephone support program had higher MLHFQ scores and lower SAnxiety scores suggesting a moderate quality of life and relatively non-stressful or neutral anxiety levels on posttest scores. Self-care scores were improved but did not meet the minimum level for adequacy. Readmission and mortality rates were below the facility and national averages.

\section{Recommendations}

A practice change which includes a structured telephone support program should be considered as a way to improve health related quality of life, self-care behavior, and reduce anxiety, 30-day readmission, and mortality in rural patients with heart failure. Additional intervention is needed to insure self-care behaviors are adequate in this patient population. 


\section{Dedication}

I dedicate this work to my husband, Dr. Richard Ansinelli, and my three sons, Christopher, Michael, and Hayden 


\section{Acknowledgements}

I want to thank my capstone chair, Dr. Susan McCrone, for always being there when I needed help, guidance, and support and for spending countless hours reviewing, editing, and providing comments on my paper. I would also like to thank my committee members, Dr. Lisa Hardman and Dr. David Bush for their encouraging words and helpful feedback, and for their willingness to take time out of their busy schedules to help me complete my project. 


\section{Contents}

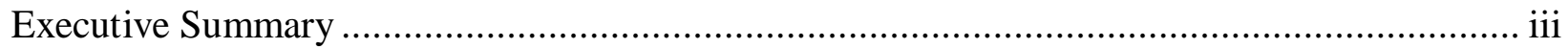

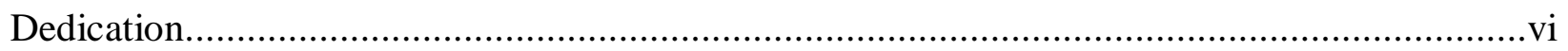

Acknowledgements ............................................................................................... vii



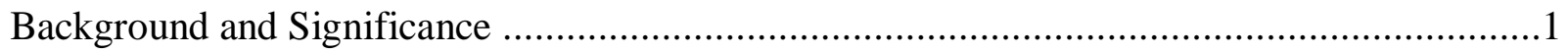

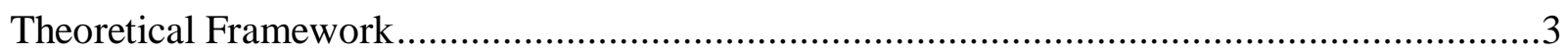

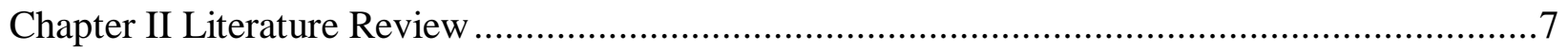

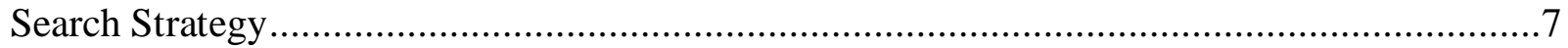



Mortality, Readmission, Quality of Life, and Self-Care ...........................................

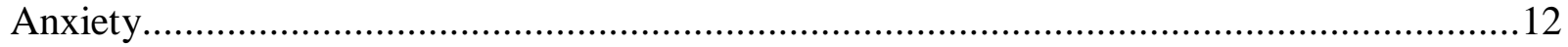

Performance Measures....................................................................................... 13

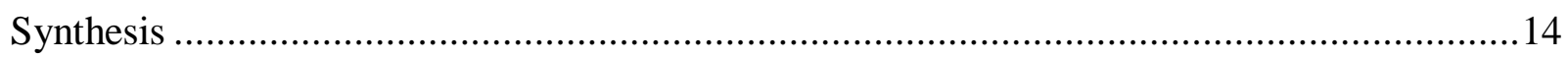

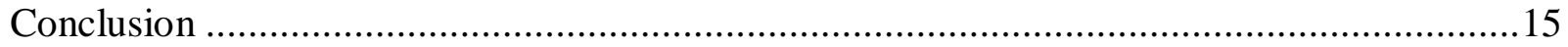

Congruence of Organizations Strategic Plan to Project ..............................................15

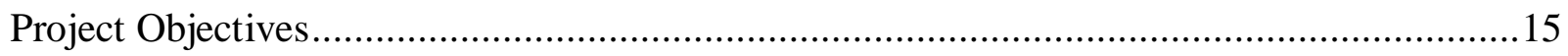

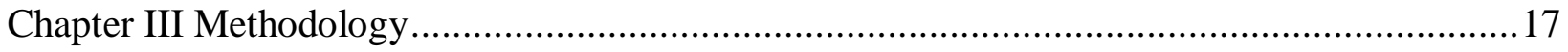

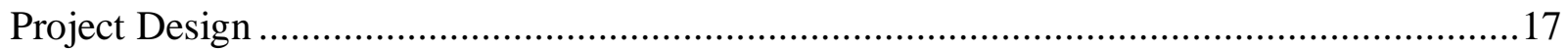

Evidence Based Project/Intervention Plan ............................................................. 17



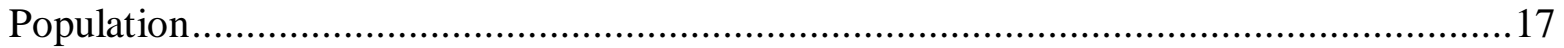

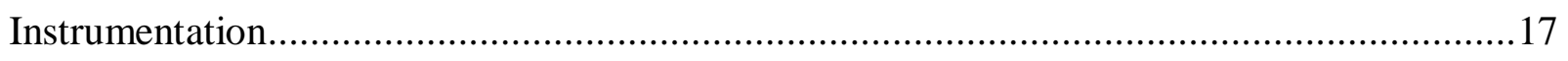

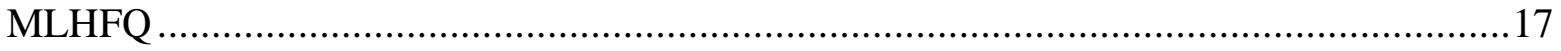

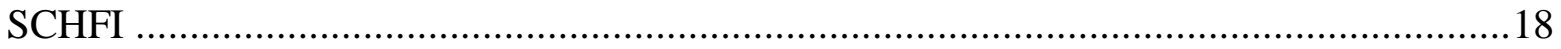

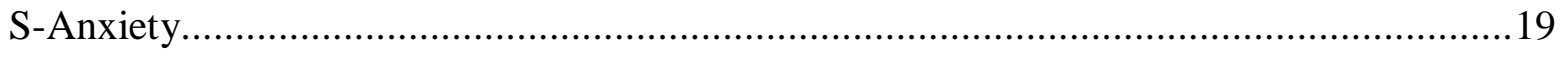

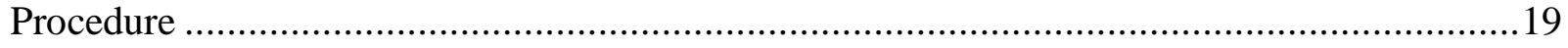

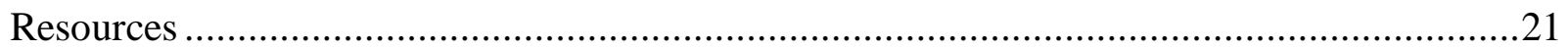




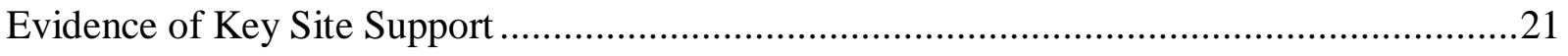

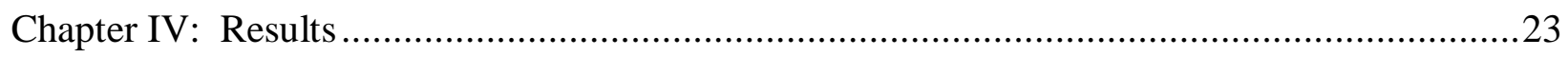

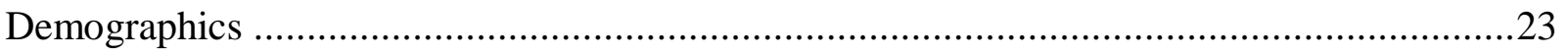

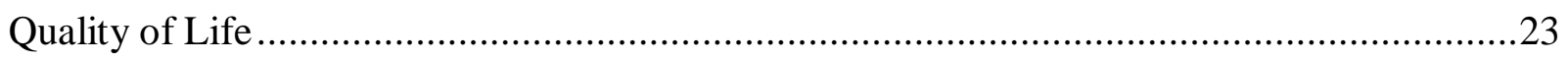

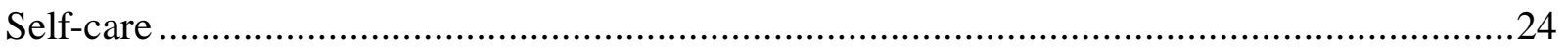

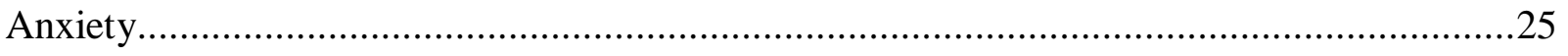

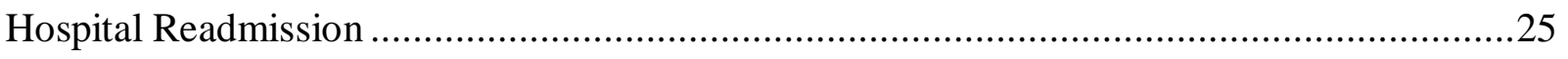

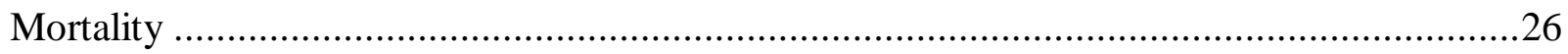

Chapter V: Discussion, Recommendations, and Conclusions................................................27

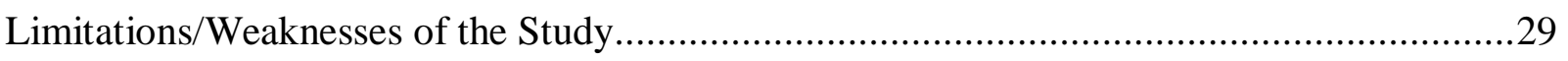

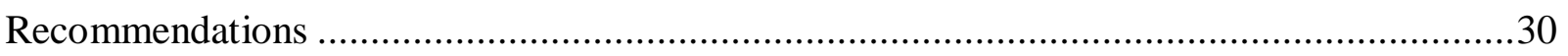

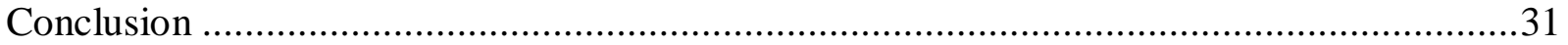

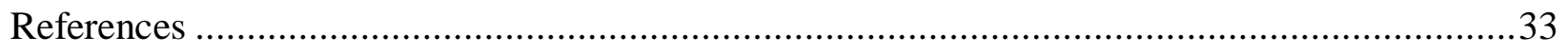

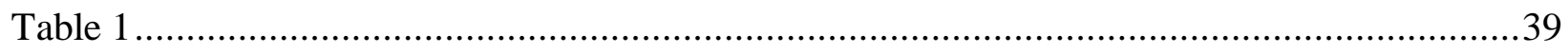

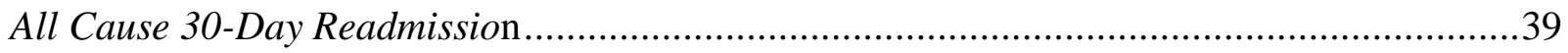

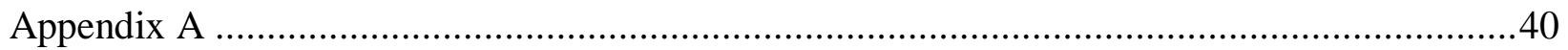




\section{Chapter I: Introduction}

\section{Background and Significance}

Heart failure (HF) is a major health issue. The treatment regimen for HF involves the use of multiple medications, fluid and dietary restrictions, lifestyle changes, and close follow-up with a health care provider. Heart failure (HF) is syndrome that is the result of a structural or functional cardiac problem that inhibits the ability of the ventricle to fill with, or eject, blood (Hunt et al., 2005). Coronary artery disease, hypertension, dilated cardiomyopathy, and valvular heart disease are common causes of HF (Hunt, et al. 2005). Hunt et al. (2005) report "in fact, any form of heart disease may lead to the development of the HF syndrome" (p. e7). The primary symptoms associated with HF are shortness of breath and fatigue; these symptoms limit exercise tolerance, cause fluid retention, and may lead to pulmonary congestion and peripheral edema (Hunt et al., 2005). There is no cure for HF, and once diagnosed, treatment is needed for the rest of the patient's life (Centers for Disease Control and Prevention [CDC], 2006).

In the United States over 5.7 million adults have a diagnosis of heart failure and nearly 670,000 more people are diagnosed with HF each year (American Heart Association [AHA], 2009). At age 40, the lifetime risk of developing HF not associated with a heart attack is 1 in 9 for men and 1 in 6 for women and increases with age (Roger et al., 2012). Patients with HF often experience cycles of treatment followed by an exacerbation of their symptoms (Berkowitz, Blank, \& Powell, 2005). Readmission to the hospital soon after being discharged with a diagnosis of HF leads to increased healthcare costs, anxiety, and a diminished health related quality of life for these patients. Krumholz et al. (2009) reported that between July 2005 and June $2008,24.4 \%$ of HF patients were readmitted to the hospital within 30 days of discharge. In 
addition to this, HF is the primary cause of approximately 55,000 deaths each year and is a contributing factor in at least 280,000 deaths annually (Roger et al., 2012).

Poor quality of care, lack of patient adherence to their treatment regimen, and problems accessing care are often cited as causes leading to an acute exacerbation of HF symptoms and subsequent hospital readmission (USDHHS, 2007). Many of these HF readmissions could be prevented through early diagnosis and treatment (CDC, 2006). Because of the high volume of heart failure diagnoses and the high cost associated with HF readmission, hospitals with higher than expected HF readmission rates will be penalized with a cut in their Medicare payments as of October 1, 2012 (Patient Protection and Affordable Care Act, 2010).

In 2007-2009, Kentucky ranked seventh in the nation for HF death rates (CDC, 2013). Radzyminski (2007) reported that the health of a population is influenced by the physical, social, cultural, and economic environment. Poverty, illiteracy, a high unemployment rate, and limited access to care are cited as reasons why the Appalachian region of Kentucky has one of the highest rates of cardiovascular disease in the developed world (Rugg, Bailey, \& Browning, 2008). In 2009, $18.4 \%$ of Kentuckians lived below the federal poverty level (United States Census Bureau, 2010). According to statistics collected between 2005 and 2009, 80.3\% of Kentuckians 25 or older graduated from high school (United States Census Bureau, 2010). In 2010, the unemployment rate in Kentucky was 10.5\% (Kentucky Workforce Statistics, 2011). Eighty-five of Kentucky’s 120 counties are considered rural (United States Department of Agriculture, 2011). The United States Department of Agriculture (2011) statistics report higher levels of poverty, higher unemployment rates, and fewer high school graduates in rural counties compared to urban counties in Kentucky. Kentucky leads the nation in the prevalence of several risk factors for the development of cardiovascular disease, including tobacco use, obesity, 
physical inactivity, diabetes, hypertension, and hypercholesterolemia (Rugg, Baily, \& Browning, 2008).

Patients living in rural Appalachia often face barriers that make access to healthcare difficult. Many patients live in isolated areas and may be unable to obtain regular care due to lack of transportation, and others live in areas where no provider is available (Huttlinger \& Purnell, 2008). It is not uncommon for these patients to travel long distances to obtain specialty healthcare. Because of this, treatment for HF symptoms may be delayed.

The majority of HF care takes place in the home and is done by the patient and his or her family, not by physicians or nurses (Riegel, 2008). HF patients must be actively engaged in their own care in order to successfully manage their disease (Riegel \& Dickson, 2008). The purpose of this study was to evaluate a home-based protocol designed to make specialty cardiac care more easily accessible to rural patients with HF. The effectiveness of a structured telephone intervention directed at improving self-care behaviors in HF patients was tested.

\section{Theoretical Framework}

A situation-specific theory of heart failure self-care (Riegel \& Dickson, 2008) was used as the theoretical framework for this project. This situation-specific theory focuses on HF selfcare as a means to achieve outcomes (Riegel \& Dickson, 2010) and is designed to give heath care providers a way to link theory, research, and clinical practice (Riegel \& Dickson, 2008). Riegel and Dickson (2008) believe that by helping healthcare providers understand how patients perform self-care, problem areas can be indentified and interventions customized to meet individual needs.

Symptom recognition is the key to successful HF self-care management (Riegel \& Dickson, 2008). If patients are to be successful at heart failure self-care, they need to be able to 
quickly recognize and take action when new signs and symptoms of worsening HF develop (Riegel \& Dickson, 2008). Patient's self-care behavior is influenced by their knowledge, experience, skill, and compatibility with their individual values (Riegel \& Dickson, 2008). The situation-specific theory of heart failure self-care postulates that as patients gain knowledge, experience, and skills about HF that are compatible with their values, they will be better equipped to make decisions about their own care (Riegel \& Dickson, 2008). The level of confidence the patient has in his or her ability to make the right decisions about their care correlates directly with outcomes; higher levels of self-care confidence lead to better outcomes (Riegel \& Dickson, 2008).

Key concepts of a situation-specific theory of heart failure self-care are: naturalistic decision making, self-care, self-care maintenance, self-care monitoring, self-care management, and self-care confidence.

- Naturalistic decision making - a process people use to make decisions. Riegel and Dickson (2008) use naturalistic decision making to illustrate the critical thinking abilities of patients to make decisions regarding their symptoms. Naturalistic decision makers have the ability to "mentally simulate an action and anticipate how it will play out" (Riegel \& Dickson, 2008, p. 192).

- Self-care - a naturalistic decision process that involves making a choice of behaviors intended to maintain physiologic stability and the individual's response to symptoms when they do occur (Riegel, Carlson, Moser, Seburn, \& Hicks, 2004). Everyone, healthy and ill, performs some level of self care on a daily basis (Riegel, Jaarsma, \& Stromberg, 2012). 
- Self-care maintenance - represents actions taken by individuals "to improve well being, preserve health, or to maintain physical and emotional stability" (Riegel, Jaarsma, \& Stromberg, 2012, p. 196).

- Self-care monitoring - refers to observations an individual makes about signs and symptoms (Riegel, Jaarsma, \& Stromberg, 2012).

- Self-care management - the process of evaluating changes in signs and symptoms to decide if action is warranted. Self-care management also includes the evaluation of the efficacy of the action taken to determine if it should be tried again in the future (Riegel, Jaarsma, \& Stromberg, 2012).

- Self-care confidence - refers to the patient's perception of his or her ability to make the right decisions regarding self-care. The level of self-care confidence will either facilitate or inhibit the relationship between self-care and positive outcomes (Riegel \& Dickson, 2010).

The self-care of heart failure model (Riegel \& Dickson, 2008) illustrates the 5 stages of self-care management. Stage 1 represents symptom monitoring and adherence to the treatment regimen (self-care maintenance). Stages 2 - 5 represent self-care management. During these stages, the patient recognizes and responds to symptoms and evaluates the efficacy of their actions. Riegel \& Dickson (2008) make the assumption that patients who are better at recognizing symptoms will also be better at evaluating their significance, implementing treatment, and making judgments as to how well the treatment worked.

According to Riegel and Dickson (2008), one of the most complex aspects of self-care is the need for decision making. They report that patients rarely use "a methodical, rational decision-making process" (Riegel \& Dickson, 2008, p. 197) and are more likely to react 
automatically and impulsively to the situation. The goal of this project was to improve HF patients' knowledge of HF self-care by providing education via a structured telephone intervention. During the intervention, evidence based dialogue focused on facilitating self-care management and increasing self-care confidence by providing the participant with information about HF symptom recognition, symptom evaluation, treatment initiation, and treatment evaluation. Emphasis was placed on weight monitoring, adherence to a low sodium diet or fluid restriction, adequate exercise, smoking cessation, and how to evaluate symptoms to determine which ones might indicate worsening of HF. Medication adherence and compliance with follow-up appointments was reinforced. The Self-care of Heart Failure Index V 6.2 (SCHFI) (Riegel, 2009) was used to measure self-care maintenance, self-care management, and self-care confidence in rural heart failure patients at the time of discharge from the hospital and 4 weeks afterwards. 


\section{Chapter II Literature Review}

\section{Search Strategy}

A search of the literature for evidence using the following electronic databases was performed: PUBMED, National Guideline Clearinghouse, Academic Search Complete, and the Cochrane Library. Key words used in the search were heart failure, telephone, telemonitoring, quality of life, self-care, anxiety, readmission, and mortality, Inclusion criteria for all data bases were studies written in English, in a peer reviewed journal, with a publication date between 1995 and 2011. Sixty-two studies were retrieved. Snowballing was used to find ten additional studies. Abstracts were reviewed and studies evaluating the effect of a telephone based program on heart failure with the outcomes of hospital readmission, mortality, quality of life, and anxiety were included. Eleven studies were selected for review based on their relevance to the topic and level of evidence. Types of studies included in this review are: one clinical guideline, one metaanalysis, two systematic reviews, four randomized controlled trials, and three prospective cohort studies.

\section{Critical Appraisal}

Two systematic reviews (Clark, Inglis, McAlister, Cleland, \& Stewart, 2007; Inglis et al., 2010), one meta analysis (Klersy, Silvestri, Gabutti, Regoli, \& Auricchio, 2009), four randomized controlled trials (RCTs) (Ferrante et al., 2010; Grancelli et al., 2003; Riegel et al., 2002; Wakefield et al., 2009); three prospective cohort studies (Friedmann et al, 2006); (Volz et al., 2011); and (Cully, Jimenez, Ledoux, \& Deswal, 2009) were critically appraised using the Scottish Intercollegiate Guidelines Network (SIGN, 2007) methodology to evaluate validity. The Appraisal of Guidelines for Research \& Evaluation (AGREE) (AGREE, 2001) instrument was used to evaluate the internal validity of the clinical guideline (Jessup et al., 2009). 


\section{Mortality, Readmission, Quality of Life, and Self-Care}

Clark, Inglis, McAlister, Cleland, and Stewart (2007) conducted a systematic review with meta-analysis of RCTs comparing remote monitoring via structured telephone support or telemonitoring to usual care for patients with HF. The methodology used to conduct the review is documented. Fourteen RCTs with a total of 4,264 patients met the inclusion criteria. Outcomes were all cause mortality, all cause readmission to the hospital, and the rate of admission to the hospital with HF exacerbation. Health related quality of life was a secondary outcome. Remote monitoring programs had a significant impact on all cause mortality. Telemonitoring showed greater benefits $(p=.003)$ than structured telephone support $(p=.06)$; the difference was not statistically significant $(\mathrm{p}=.18)$. In this review, there was no benefit on all cause readmission to the hospital. All studies showed a relative reduction $(\mathrm{p}=.76)$ in hospital readmissions as a result of $\mathrm{HF}$. Health related quality of life was measured in 6 studies, with 3 reporting a significant improvement in health related quality of life between the intervention and the control groups.

A meta-analysis by Klersy et al. (2009) examined the effects of remote patient monitoring (RPM) on mortality and hospitalization rates in patients with HF. Remote monitoring was conducted via scheduled structured telephone contact between the patient and the healthcare provider or telemonitoring involving the transfer of electronic physiologic data from the patient to the healthcare provider. Twenty RCTs and 12 cohort studies qualified for inclusion. The search strategy was described in detail. Inclusion and exclusion criteria were described. The primary endpoint of the study was the comparison of the incidence of events between the usual care group and patients receiving RPM. Results of the study revealed that RPM significantly reduced the risk of death and all cause hospitalization compared with usual 
care. A major strength of this study was that it represents the largest number of meta-analyzed HF patients. Most of the cohort studies were published in the last 5 years indicating a growing interest in using RPM in the management of patients with HF. In the cohort studies, the incidence of hospitalization $(\mathrm{p}=.0001)$ or death $(\mathrm{p}=.001)$ was significantly lower in the RPM group compared to the usual care group. Overall death, hospitalization for all cause, hospitalization for HF, or combined death and hospitalization was lower in the RPM group compared with the usual care group. In the RCT groups, RPM was associated with a lower number of deaths compared with usual care $(p=.0006)$.

The randomized Trial of Telephone Intervention in Chronic HF (DIAL) trial (Grancelli et al., 2003) analyzed the effect of a telephone intervention in reducing death or admission for HF exacerbation and improving the health related quality of life in patients with chronic HF. This was a multicenter RCT with 1,518 participants. GESICA investigators (2005) reported that patients in the usual care group were more likely to be admitted for HF or to die $(31 \%)$ than those in the intervention group $(26.3 \%)(\mathrm{p}=.026)$. The intervention group also reported a better health related quality of life $(p=.001)$ than the control group.

Ferrante et al. (2010) reported a follow-up on the rate of death and hospitalization for HF patients at 1 and 3 years after the DIAL telephone intervention study was completed. One year after the intervention ended, there was a $19 \%$ reduction in the primary endpoint of combined rate of death or hospitalization for heart failure $(\mathrm{p}=.013)$ and at 3 years a $12 \%$ reduction $(\mathrm{p}=.05)$. This was the first study to show the long term effects of a telephone based intervention for HF patients.

Inglis et al. (2010) conducted a systematic review of RCTs evaluating the effect of structured telephone support versus telemonitoring programs in patients with HF. Only peer 
reviewed published RCTs were included. Twenty five studies with a total 8,423 participants were chosen. The description of the methodology used to conduct the review is well documented. Patients in the structured telephone support arm received phone calls initiated by the healthcare provider to discuss concerns and problems. Patients in the telemonitoring arm used telemonitoring equipment to transfer electronic physiologic data to the healthcare provider.

Primary outcomes were all cause mortality and all cause and HF related hospitalizations. Other outcomes reported in this systematic review were length of stay, health related quality of life, acceptability, and cost. The review found that structured telephone support had a nonsignificant positive effect on mortality with $\mathrm{p}<.08$, while telemonitoring was found to reduce all cause mortality $(\mathrm{p}=.0001)$. Both interventions were found to equally reduce all cause $(\mathrm{p}=.02)$ and HF hospitalization for structured telephone support $(\mathrm{p}=.0001)$ and for telemonitoring $(\mathrm{p}=$ .0001). Researchers also noted improved health related quality of life, reduced healthcare costs, improvement in knowledge and self-care, and improvement in New York Heart Association functional class. There was a strong publication bias towards positive outcomes in the studies included in the review (Inglis et al., 2010). The authors concluded that structured telephone support and telemonitoring are effective ways to reduce mortality and hospitalizations in patients with HF. These interventions were also found to reduce healthcare costs and improve health related quality of life in HF patients (Inglis et al., 2010).

In a study by Riegel et al. (2002), investigators evaluated the effectiveness of standardized telephone case management to decrease resource use in patients with HF. Two hundred and twenty-eight patients with HF were identified at hospitalization and were randomized according to their attending physician to an intervention or a usual care group. The attending physicians were blinded to their patients' assignment. Outcomes measures included: 
hospitalization rates, heart failure readmission rates, and patient satisfaction at three and six months. The intervention group was phoned within five days of hospital discharge and then again at a frequency determined by software provided by Pfizer Pharmaceuticals. Patients received an average of 17 phone calls at decreasing levels of intensity, length, and frequency (Riegel et al., 2002). Patients received printed educational materials via mail on a monthly basis. HF hospitalization rates were $45.7 \%$ lower in the intervention group than in the usual care group at 3 months $(\mathrm{p}=.03)$ and $47.8 \%$ lower at 6 months $(\mathrm{p}=.01)$. Although patient satisfaction data was not available from all the patients, patient satisfaction was significantly higher in patients assigned to the intervention group. A limitation of the study is the randomization according to their attending physician and not by the patients themselves (Riegel et al., 2002).

Wakefield et al. (2009) compared two types of telehealth interventions, one using a telephone and one using a videophone, for patients receiving usual HF care. Outcomes of the study included self-efficacy, readmission rates, time to readmission, and mortality. Intervention patients were randomized to telephone intervention and videophone intervention. Interventions “consistent with American Heart Association Guidelines" (Wakefield et al., 2009, p.47) were conducted by registered nurses and included a maximum of 14 contacts over 90 days. Intervention contacts lasted for 34-37 minutes. One hundred and forty- eight patients were enrolled. Participants in the intervention group were found to have a longer time to readmission. There was no effect on readmission or mortality rate. Researchers found no differences among the groups in terms of medication compliance but did note higher overall knowledge scores in the intervention group. Researchers noted that medication reconciliation was a limitation in the study because the electronic medical record at the time of discharge only included medications provided by VA doctors, and not over the counter medications or medications prescribed by 
other providers. Another limitation of this study was that diet, fluid, and sodium intake were not measured.

\section{Anxiety}

Volz et al. (2011) examined the effect of anxiety on hospital readmission, mortality, and health related quality of life in 111 patients with chronic heart failure. Researchers concluded that HF patients with severe anxiety were three times more likely to have a cardiac related readmission than those participants without anxiety. However, this effect was not significant if the patient had social support. Additionally, psychological variables were found to have a negative impact on health related quality of life. No link between anxiety and mortality was found. This study had several limitations, including a small sample size and possible selection bias. Patients recruited for the study were participants in a cardiac rehabilitation program, which may have excluded possible participants with more psychological issues and more severe heart failure.

Friedmann et al. (2006) reported on the prevalence of anxiety and its relationship to mortality in patients with heart failure. The 153 participants in the study were enrolled from the Sudden Cardiac Death Heart Failure Trial. Researchers confirmed that anxiety is common in heart failure patients. Forty -two percent of the participants reported having significant anxiety. Researchers concluded that patients who were anxious had a $12 \%$ mortality rate compared to a mortality rate of $8 \%$ in those who did not report anxiety.

Cully, Jimenez, Ledoux, and Deswal (2009) conducted a prospective study focusing on the prevalence, recognition, and treatment of anxiety and/or depression in patients with heart failure. A total of 158 patients were enrolled in the study. Participants completed a telephone survey focusing on heart failure severity, depression, and anxiety. Based on screening results, 
the investigators concluded that $25.3 \%$ of the participants suffered from anxiety, and $41.8 \%$ were depressed. Researchers then reviewed each participant's electronic medical record (EMR) from 12 months before the study to 6 months after the study looking for a diagnosis and treatment of anxiety and/or depression. They found that $57.5 \%$ of the patients with a positive anxiety or depression screen had a diagnosis or notation of anxiety and/or depression in their EMR; $60.3 \%$ of these patients received treatment during the 18 month period. In patients with a documented diagnosis of anxiety and/or depression independent of screening results, 92.3\% received treatment. Researchers concluded that symptomatic anxiety and/or depression in heart failure patients may be overlooked. Screening for these conditions and documenting findings in the patient's medical record can help to make a definitive diagnosis of anxiety and/or depression which in turn will likely lead to treatment.

\section{Performance Measures}

The 2009 Focused Update: American Heart Association/American College of Cardiology Guidelines for the Diagnosis and Management of Heart Failure in Adults (Jessup et al., 2009) is intended to assist healthcare providers by providing recommendations for the diagnosis, management, and prevention of HF. Class I recommendations for patients with heart failure include: diuretic therapy, sodium restriction, angiotensin converting enzyme (ACE) inhibitors, betablockers, angiotensin II receptor blockers (ARB's), withdrawal of drugs known to adversely affect patients with HF, exercise training, and implantable cardioverter-defibrillators in patient's meeting criteria for this device. The guideline emphasizes education of the patient and/or caregiver at the time of discharge. The guideline recommends that written educational materials and instructions be given to the patient and/or caregiver at the time of discharge (Jessup et al., 2009). Written discharge instructions should include: activity level, diet, discharge mediations, 
follow-up appointment, weight monitoring, and what to do if symptoms worsen (Jessup et al., 2009). Post discharge support is recommended for older adults to reduce hospital readmission rates, improve survival, and improve quality of life (Jessup et al., 2009).

\section{Synthesis}

Eleven studies met criteria for inclusion in this review. Five studies addressed telephone support and mortality in heart failure patients. Three studies examined the relationship between anxiety and heart failure, and one clinical practice guideline outlines performance measures for heart failure care.

Clark et al. (2007), Kelsey et al. (2009), Grancelli et al. (2003), and Ferrante et al. (2010) found decreased rates of mortality in the intervention group. Wakefield et al. (2009) found no difference in mortality rates between the intervention and the control group. Inglis et al. (2010), Riegel et al. (2002), Grancelli et al. (2003), and Ferrante et al. (2010) found statistically significant reductions in hospital readmission rates for heart failure in patients receiving telephone support. Clark et al. (2007) and Wakefield et al. (2009) found no difference in heart failure readmission rates between the two groups.

Two systematic reviews (Clark et al., 2007; Inglis, 2010) and one RCT (Grancelli et al., 2003) reported a significant improvement in health related quality of life of heart failure patients with a structured telephone intervention.

Wakefield et al. (2009) reported higher knowledge scores after the telephone intervention; however, they noted lower scores in the intervention at enrollment compared to the control group.

Volz et al. (2011) and Friedmann et al. (2006) studied the effect of anxiety on mortality in patients with HF. Volz et al. (2011) found no link between anxiety and mortality in this 
patient population, while Friedman et al. (2006) found patients with HF had a greater likelihood of mortality. In addition, Volz et al. (2011) found that patients with anxiety and without social support were more likely to be readmitted to the hospital. Researchers also concluded that anxiety had a negative impact on health related quality of life. Cully, Jimenez, Ledoux, and Deswal (2009) documented the benefit of telephone screening for anxiety and depression in HF patients. Jessup et al. (2009) provided evidence based guidelines for inpatient treatment and transition to outpatient care of the HF patient.

\section{Conclusion}

Although the findings are mixed, there is sufficient evidence to support the feasibility of a project to assess the effectiveness of a structured telephone program in reducing hospital readmission and mortality rates, improving health related quality, improving self-care, and reducing anxiety in patients with heart failure.

\section{Congruence of Organizations Strategic Plan to Project}

The mission statement of the participating cardiology group in this project is "to care, to serve, to heal, and to provide world class care in our communities". These values are reflected in this capstone project. The primary goal of the project is to improve access to specialized cardiac care for HF patients living in rural eastern Kentucky.

\section{Project Objectives}

The goal of this project was to evaluate the effectiveness of a structured telephone program in improving quality of life and self care behaviors, and reducing anxiety, 30 day readmission rates, and mortality in rural patients with HF. After participating in the structured telephone support program participants will report: 
1. Lower health related quality of life scores on the Minnesota Living with Heart Failure Questionnaire (MLHFQ) (Rector \& Cohn, 2005) indicating improved quality of life.

2. Higher scores on the SCHFI V 6.2 (Riegel, 2004) indicating improved health care behaviors

3. Lower scores on the state anxiety (S-Anxiety) subscale of the State-Trait Anxiety Inventory (STAI) (Spielberger, Lushene, \& Gorsuch, 1983) indicating reduced anxiety.

4. Lower hospital readmission rates.

5. Lower mortality rates. 


\section{Chapter III Methodology}

\section{Project Design}

Evidence Based Project/Intervention Plan. A quasi experimental one group, pretest, posttest design was used to determine the effectiveness of a structured telephone intervention on health related quality of life, anxiety, and self-care behaviors in patients hospitalized with heart failure. The investigator served as the project coordinator.

Setting. The setting for this project was an outpatient cardiology specialty clinic located in the foothills of the Appalachian Mountains in rural eastern Kentucky. The clinic is one of 3 outpatient cardiology clinics located in rural eastern Kentucky operated by a regional heart center located approximately 50 miles north. Three cardiologists and 3 nurse practitioners provide both inpatient and outpatient cardiac care.

Population. Patients were considered to be eligible to participate in the study if they were admitted to the hospital with a diagnosis of HF and were seen in consult by a member of the participating cardiology group. They had to be at least 18 years old, speak English, be able to give written consent, and have access to a telephone. Nursing home residents, patients without a telephone, patients with impaired cognition, and patients not under the care of the participating cardiology group were excluded. Participation in the study was voluntary. Written consent to participate was obtained.

\section{Instrumentation}

MLHFQ. The MLHFQ (Rector \& Cohn, 2005) was used to measure the effect of heart failure and its treatment on participant's health related quality of life. Olatz et al. (2009) conducted a systematic review with meta-analyses of five disease-specific health-related quality of life questionnaires. The MLHFQ was the most commonly used instrument for measuring 
health related quality of life clinical trials. The MLHFQ has been proven to have an adequate level of reliability with a Cronbach's alpha coefficient reported of .94 [95\% CI: 0.91-0.95] with extensive evidence to support the MLHFQ's responsiveness and ability to measure change in patient's health related quality of life (Olatz et al., 2009).

The MLHFQ consists of 21 questions pertaining to symptoms, functional limitations, and stresses commonly associated with heart failure (Rector \& Cohn, 2005). Study participants were asked to answer each question on a 6-point Likert scale of 0 to 5 with zero being none and 5 being very much regarding the effect of the symptom, limitation, or stress on their ability to live as they desire (Rector \& Cohn 2005). Possible scores range from a minimum of 0 to a maximum of 105. Each questionnaire takes approximately 5-10 minutes to complete. A license is required to use the MLHFQ and was obtained by the project coordinator.

SCHFI. The SCHFI V 6.2, developed in 2004 and updated in 2009, is designed to evaluate self-care behaviors in patients with heart failure (Riegel, 2009). The SCHFI consists of 22 questions that are rated on a 4-point Likert scale. The instrument is divided into three subsections. Section A of the SCHFI, self-care maintenance (10 questions), measures the ability of the respondents to monitor their symptoms and to follow prescribed treatment regimens. Section B, self-care management (6 questions), evaluates the respondents' ability to recognize symptoms of worsening heart failure, to take action to alleviate their symptoms, and to determine how well these actions worked. Only patients who reported edema or shortness of breath during the previous month are asked to complete this section B. Section C, self-care confidence (6 questions), measures respondents' confidence in their ability to perform HF self-care (Riegel \& Dickson, 2008). 
Each section is scored separately. A score of 70 or greater on each section is considered sufficient for self-care but benefits can occur at lower levels (Riegel, Lee, Dickson, \& Carlson, 2009). Riegel et al. (2009) reported alpha coefficient of section A (maintenance) of .553, section $\mathrm{B}$ (management) .597, and section C (confidence) .827. Both qualitative and quantitative approaches were used to document adequate validity of the SCHFI (Riegel, et al., 2009) The SCHFI takes approximately five minutes to complete and can be taken directly by the respondent or in an interview setting (Riegel et al., 2004). Permission is not needed to use this instrument.

S-Anxiety. The S-Anxiety subscale of the STAI (Spielberger, Gorsuch, Lushene, Vagg, \& Jacobs, 1983) was used to measure respondents' anxiety levels. The S-Anxiety scale is comprised of 20 statements asking the respondent to describe how he or she is feeling "right now at this moment" (Spielberger et al., 1983, p. 6). Items are scored on a scale of 1 to 4 with 4 indicating high anxiety on 10 items and 4 indicating no anxiety on the remaining 10 items. Scores range from a minimum of 20 to a maximum of 80 . Test retest reliability for the SAnxiety subscale is .53 (Spielberger et al., 1983). This instrument has been used extensively for measuring anxiety in patients with chronic illnesses and validity has been shown (Spielberger, Lushene, \& Gorsuch, 1983). Permission is required to use this questionnaire and was obtained by the project coordinator.

\section{Procedure}

A convenience sample of 30 participants was selected to participate in the program. The American College of Cardiology/American Heart Association (ACC/AHA) 2005 Guideline Update for the Diagnosis and Management of Chronic Heart Failure in the Adult (Hunt et al., 2005) evidence-based clinical performance measures were used to evaluate the treatment plan for patients participating in the project. These measures included: left ventricular systolic function 
assessment, angiotensin-converting enzyme (ACE) inhibitors or Angiotensin II Receptor Blockers (ARB's) at discharge in patients with a left ventricular ejection fraction of less than $40 \%$, anticoagulant at discharge for patients with chronic or recurrent atrial fibrillation, and smoking cessation advice and counseling. Participants were provided with written evidencebased educational material at the time of discharge with Flesh Kinkaid Grade-Levels scores ranging from 6 to $11^{\text {th }}$ grades. These materials were reviewed with the patient. After obtaining consent and prior to leaving the hospital, study participants were asked to complete the MLHFQ, SCHFI, and the S-Anxiety subscale of the STAI. These instruments were read to the participant and scored by the project coordinator using methods defined by the developers

The structured telephone intervention consisted of a series of five telephone calls to the participant after discharge from the hospital. The first telephone call took place approximately 72 hours after discharge from the hospital as recommended by Get With The Guidelines ${ }^{\circledR}$ Heart Failure (AHA, 2013) the AHA's quality improvement program intended to reduce hospital readmission rates in patient with heart failure. Subsequent calls took place on a weekly basis thereafter. A total of 96 telephone contacts were completed to include at least one intervention and posttesting for each participant. An evidence based script (“Telephone Follow-up Form”, n.d.) was used to guide the intervention. Dialogue included ensuring that follow-up appointments were made and new prescriptions were filled. Study participants were also provided with information based on their individual needs regarding medications, adherence to the medication regimen, diet, exercise, risk reduction, monitoring for signs and symptoms of worsening heart failure, and what to do if symptoms became worse. Appropriate referrals were made for unfilled prescriptions, worsening symptoms, and to schedule follow-up appointments. 
During the final telephone call, the MLHFQ, SCHFI, and the S-Anxiety subscale of the STAI were readministered.

Protocol for this study was approved by the West Virginia University Institutional Review Board (IRB). Participation was voluntary. No adverse events were reported during the course of this study. Confidentiality of the participants was maintained by assigning identification numbers to each patient. No information has been publically reported in a manner that identifies the participant. Only the project coordinator has access to the information provided by the participant.

\section{Resources}

Monetary resources required for this capstone project were approximately $\$ 200$. Telephone resources were provided by the capstone coordinator and the capstone site at no charge. The Minnesota Living with Heart Failure Questionnaire is provided to students at no cost. The STAI required a license for use and cost $\$ 100$ to reproduce 50 copies (the minimum number) of the instrument. The project coordinator purchased and distributed 5 weight scales at the cost of \$20 each. Tracking, educational materials, and discharge instructions were downloaded from the Institute for Healthcare Improvement (IHI) (2008) website and were photocopied at the capstone site at no additional cost. The telephone script was downloaded from the American Heart Association website and was photocopied at the capstone site at no additional cost. Additional resources for this project include West Virginia University (WVU) professors, capstone chair, committee member, and the project coordinator's collaborating physician.

\section{Evidence of Key Site Support}


The project has approval from the project coordinator's collaborating physician and practice administrator to recruit participants for the project affiliated with the participating cardiology group (see Appendix A for letter of support). 


\section{Chapter IV: Results}

\section{Demographics}

A total of 30 patients completed the study. One additional patient agreed to participate in the study but was lost to follow-up. Two additional patients who met inclusion criteria for the study refused to participate. Other heart failure patients admitted to the hospital during the recruitment phase of the study were excluded because of physical or cognitive disabilities or were residents of a nursing home. The final sample consisted of 17 men and 13 women. The average age of study participants was 66.43 (range 48-85). Forty percent were married; 100\% of the study participants were Caucasian; $57.6 \%$ of the study participants completed high school. One participant completed college. The average ejection fraction of the study participants was 44.53 (range 15\%-67\%). Thirty percent of the study participants had a diagnosis of anxiety, $20 \%$ had a diagnosis of depression.

\section{Quality of Life}

The MLHFQ score reflects how heart failure and its treatment impact an individual's quality of life. Possible scores range from zero to 105. A higher score indicates a lower quality of life and a lower score indicates a higher quality of life. Pretest scores ranged from 30 to 65. Posttest scores ranged from 24 to 56 . Data revealed twenty nine study participants had lower scores on the posttest while one participant had a higher score. A paired samples t-test was conducted to evaluate the impact of the intervention on participant's MLHFQ scores. There was a statistically significant decrease in scores on the MLHFQ from the pretest $(M=48.23, \mathrm{SD}$ $8.74)$ to the posttest $(M=40.4667, \operatorname{SD} 9.878), \mathrm{t}(29)=11.056, \mathrm{p}<.005$ (one tailed). The mean decrease in MLHFQ scores was 7.767 with a 95\% confidence interval ranging from 6.330 to 9.203. In the current study, the Cronbach's alpha coefficient was .765 pretest and .789 posttest. 


\section{Self-care}

Scores for Section A- Self-care Maintenance are calculated on a 100 point scale. Scores on the pretest ranged from 26.664 to 79.992 . Scores on the posttest ranged from 29.997 to 79.992. Scores of less than 70 are considered to reflect inadequate self-care abilities. Two study participants had no change in their pretest and posttest scores. Twenty eight study participants demonstrated improvement in self-care maintenance scores. None of the study participants had a decline in self-care maintenance scores. A paired samples t-test was conducted to evaluate the impact of the intervention on participant's scores on the SCHFI Section A. There was a statistically significant increase in SCHEFI A scores from pretest $(\mathrm{M}=$ $50.438, \mathrm{SD}=13.353)$ to posttest $(\mathrm{M}=59.661, \mathrm{SD}=12.993), \mathrm{t}(29)=7.733, \mathrm{p}<.0005$ (onetailed). The mean increase in SCHFI A scores was 9.221 with a $95 \%$ confidence interval ranging from 6.782 to 11.660 . In the current study, the Cronbach's alpha coefficient was .635 pretest and .792 posttest.

Scores for Section B- self-care Management were calculated on a 100 point scale. Scores $(\mathrm{N}=30)$ on the pretest ranged from 10 to 80 on the pretest. Only study participants $(\mathrm{N}=25)$ who reported having shortness of breath in the month prior to the posttest were asked to answer questions in section B. Scores $(\mathrm{N}=25)$ on posttest ranged from 30 to 85 . All 25 study participants had higher posttest scores in self-care management. A paired samples t-test was conducted to evaluate the impact of the intervention on participant's scores. There was a statistically significant increase in SCHFI B scores from pretest $(M=44.80$, SD 19.120) to posttest $(\mathrm{M}=55.40, \mathrm{SD} 15.540), \mathrm{t}(24)=5.338, \mathrm{p}<.005$ (one-tailed). The mean increase in SCHFI B scores was 10.600 with a $95 \%$ confidence interval ranging from 6.502 to 14.698 . In the current study, the Cronbach's alpha coefficient was .717 pretest and .716 posttest. 
Scores for Section C - self-care confidence were calculated on a 100 point scale. Scores on the pretest ranged from 33 to 100 . Posttest scores ranged from 33.36 to 100 . Fifteen study participants reported no change in their self confidence scores. Fifteen study participants reported increased self-care confidence. A paired samples t-test was conducted to evaluate the impact of the intervention on the participant's scores. There was a statistically significant increase in SCHFI C scores from pretest $(M=57.077, S D 19.022)$ to posttest $(M=61.340, S D$ 17.322), $\mathrm{t}(29)=4.490, \mathrm{p}<.005$ (one-tailed). The mean increase in SCHFI C scores was 4.262 with a $95 \%$ confidence interval ranging from 2.321 to 6.204 . In the current study, the Cronbach's alpha coefficient was .861 pretest and .884 posttest.

\section{Anxiety}

The S-Anxiety subscale of the STAI was used to measure anxiety. Possible scores ranged from 20 to 80 . Scores of 35 to 40 are considered to be relatively non-stressful or neutral. A higher score indicates increased anxiety while a lower score indicates less anxiety. Pretest scores in the study ranged from 26 to 71 . Posttest scores ranged from 25 to 69 . Twenty nine study participants had lower scores on the posttest while one participant had no change in the pretest and posttest score. A paired samples t-test was conducted to evaluate the impact of the intervention on participant's STAI scores. There was a statistically significant decrease in SAnxiety scores from pretest $(M=39.5667$, SD 9.073$)$ to the posttest $(M=36.8333$, SD 8.469), $t$ $(29)=5.634, p<.005$ (one tailed). The mean decrease in S-Anxiety scores was 2.733 with a 95\% confidence interval ranging from 1.691 to 3.775 . In the current study, the Cronbach's alpha coefficient was .936 pretest and .937 posttest.

\section{Hospital Readmission}


Seven study participants (23\%) were readmitted to the hospital within 30 days over the course of the study. Three study participants were readmitted with HF exacerbation. One participant was readmitted with chest pain, one with an upper respiratory infection and bronchitis, and one with numbness all over. One patient was readmitted for a diagnostic cardiac catheterization and subsequent treatment. The average facility 30-day readmission rate for hospitals included in this study is $27.15 \%$ based on 437 eligible admissions for this measure. The national 30 -day readmission rate for heart failure is $24.7 \%$. Table 1 summarizes scores on the MLHFQ, SCHFI, and the S-Anxiety subscale of the STAI in patients who were readmitted.

\section{Mortality}

None of the study participants died during the study. The average 30 -day mortality rate for hospitals included in the study is $6.6 \%$ based on 362 eligible admissions for this measure. The national 30 -day mortality rate for heart failure is $11.6 \%$. 


\section{Chapter V: Discussion, Recommendations, and Conclusions}

The health of a population is influenced by the physical, social, cultural, and economic environment (Radzyminski, 2007). Limited access to care has been cited as a reason why the Appalachian region of Kentucky has one of the highest rates of cardiovascular disease in the developed world (Rugg, Bailey, \& Browning, 2008). Kentucky ranked seventh in the nation for HF death rates in 2007-2009 (CDC, 2013). The objectives of this project were to evaluate the effectiveness of a structured telephone support program for home-based HF management in improving quality of life and self-care behaviors, reducing anxiety, 30 day readmission rates, and mortality rates in rural patients with heart failure.

There was a significant decrease in mean scores on the MLHFQ suggesting an improvement in quality of life. All but 7 reported that they did not have to stay in the hospital. Most reported improvement in their physical symptoms (swelling, shortness of breath, and fatigue) related to HF. Two systematic reviews (Clark et al., 2007; Inglis, 2010) and one RCT (Grancelli et al., 2003) also reported a significant improvement in health related quality of life of heart failure patients after a structured telephone intervention.

Following the structured telephone intervention, participants had higher score on the SCHFI suggesting better self-care maintenance, self-care management, and higher self-care confidence. However, scores were not high enough to be considered adequate. Most participants reported that they never or rarely forgot to take their medications and had confidence

that they would be able to follow their treatment regimen. Patients who had symptoms of edema or shortness of breathe in the month prior to the posttest reported that they were most likely to call their doctor or nurse for advice and less likely to take an extra diuretic. Wakefield et al. (2009) also reported higher knowledge scores after the telephone intervention; however, they 
noted that the higher score may have been due to the fact that scores were lower in the intervention group at enrollment compared to the control group.

Anxiety score were significantly lower on the posttest S-Anxiety scale of the STAI supporting the benefit of screening this patient population. Cully, Jimenez, Ledoux, and Deswal (2009) documented the benefit of telephone screening for anxiety and depression in HF patients. Volz et al. (2011) and Friedmann et al. (2006) studied the effect of anxiety on mortality in patients with HF. Volz et al. (2011) found no link between anxiety and mortality in this patient population, while Friedman et al. (2006) found patients with HF had a greater likelihood of mortality. In addition, Volz et al. (2011) found that patients with anxiety and without social support were more likely to be readmitted to the hospital. Researchers also concluded that anxiety had a negative impact on health related quality of life.

Hospital readmission rates were lower than the facility and national averages. These finding are similar to those reported by Inglis et al. (2010), Riegel et al. (2002), Grancelli et al. (2003), and Ferrante et al. (2010) who found statistically significant reductions in hospital readmission rates for heart failure in patients receiving telephone support. However, Clark et al. (2007) and Wakefield et al. (2009) found no difference in heart failure readmission rates between the two groups.

Pre and posttest scores on the MLHFQ, SCHFI, and the S-Anxiety subscale of the STAI of the 7 patients readmitted to the hospital within 30 days of discharge were analyzed. Prior to the structured telephone intervention, 5 of these patients had higher scores (suggesting poorer quality of life) than the mean score of 48.23 for the group as a whole on the MLHFQ. Four patients had higher than average ( $\mathrm{M}=50.438)$ scores on SCHFI A (self-care maintenance), 3 patients had higher SCHFI B scores than the average $(\mathrm{M}=44.8)$, and 3 patients had higher scores than the average (57.077) on SCHFI C. All but 2 patients had lower than average (M= 
39.5667) scores on the S-Anxiety subscale STAI. These findings suggest that higher self-care scores did not prevent readmission in these patients and that those with lower quality of life scores are more likely to be readmitted. In this study, state anxiety does not appear to play a role in 30-day hospital readmissions.

None of the subjects in this study died during the 4 weeks they were participants in this study. Improved health related quality of life and self-care behaviors, along with lower anxiety levels may have contributed to this finding. Clark et al. (2007), Kelsey et al. (2009), Grancelli et al. (2003), and Ferrante et al. (2010) found decreased rates of mortality in the telephone intervention group. Wakefield et al. (2009) found no difference in mortality rates between the intervention and the control group.

\section{Limitations/Weaknesses of the Study}

Non-probability sampling was used and findings from this study cannot reliably be generalized to the total population of heart failure patients. Additionally, it would have been beneficial to have a control group to use for comparison to aid in describing the intervention effects. All information was self-reported by the participants.

Low self-care scores may have been increased by including caregivers in the telephone support program. In addition to this, it is also possible that 4 weeks is not enough time for patients to learn adequate self-care of heart failure behaviors. Timing of the administration of the pretest MLHFQ and the S-Anxiety subscale of the STAI may have influenced participants' responses to some degree. Pretesting was performed at the time of hospitalization for an acute event; posttesting was completed after the participant was at home for a month. The MLHFQ asks the patient to think about how heart failure has affected them during the past month. At the time of the pretest, this would have been the time period leading up to the hospitalization which typically involves an exacerbation of symptoms. After treatment, symptoms are typically 
improved. Question 14 "making you stay in the hospital" was especially problematic. Scoring for this question is a "0" for no and " 5 " for very much. All participants were "very much" in the hospital during the pretest period and scored " 5 " and a " 0 " for "no" one month later if they were not readmitted. This may have caused abnormally high pretest scores for quality of life and anxiety. Additionally, there was no way to control other variables that may have affected participants' quality of life, self-care behaviors, and anxiety levels. It was somewhat difficult to obtain numerical answers to questions on the MLHFQ, SCHFI, and S-Anxiety subscale over the phone. Lastly, some of the written educational materials may have been too complicated for every participant to understand.

\section{Recommendations}

This type of intervention can be used on HF patients who are without physical and/or cognitive deficits that might prevent them from using the telephone. Screening can be used to identify those patients who could benefit most from receiving phone calls from a health care provider. Contacting all HF patients by telephone 72 hours after discharge from the hospital is recommended to ensure arrangements are made for follow-up and to ensure that any questions or concerns are addressed in a timely fashion. This call can prevent the patient from becoming lost in the system, especially if they're discharged on the weekend and a follow-up appointment is not given to them prior to discharge. The need for subsequent follow-up calls can then be determined based on the severity of the patient's illness. Prior to discharge from the hospital and again during the initial telephone intervention, patients should be provided with the name and telephone number of a heath care provider who is capable of answering their questions and managing their care on an ongoing basis.

Administration of the SCHFI prior to discharge from the hospital is a way for providers to identify areas of self-care maintenance, self-care management, and self-care confidence 
needing reinforcement allowing them to tailor educational efforts to meet the patient's needs during follow-up telephone calls and clinic visits. Providers should consider using the MLHFQ and an anxiety survey at one month post hospitalization and periodically after that to identify potential issues that may be adversely affecting the patient. Ideally, this could be done in the clinic setting. If these instruments are administered over the telephone, each session should include only one instrument to avoid fatigue.

An "in clinic" education session should be scheduled with the patient soon after discharge from the hospital. This offers the opportunity for the provider to use visual props designed to help the patient understand the importance of compliance with medications, reading labels, following a low salt diet, using a weight scale, measuring fluids, keeping a weight diary, and to observe the patient's non-verbal behaviors. This setting also allows the patient to have an opportunity to for a "hands on experience" with the tools necessary to manage their illness while a health care professional is available to answer questions. Family members or significant others who are involved in the HF patient's care at home should be included in any education sessions. Finally, patients and caregivers should be interviewed with the goal identifying any perceived barriers are to ongoing HF care and to determine how we can better meet their individual needs.

\section{Conclusion}

Heart failure and its treatment can have devastating effects on patients' lives. Structured telephone support is a good way for the rural HF patient to remain at home and still maintain close contact with his or her health care provider(s). As an adjunct to clinic follow-up, it provides a means to educate HF patients about their illness and to teach them how to monitor and manage symptoms associated with HF exacerbation. The frequency and duration of the calls can be tailored to meet the individual patients' needs. Ultimately, better self-care behaviors can 
improve the patients' health related quality of life, reduce anxiety, lead to fewer hospitalizations, and decrease mortality in this patient population. 


\section{References}

American Heart Association. (2009). Heart Disease and Stroke Statistics-2009 Update. Dallas, TX: American Heart Association.

American Heart Association. (2013). Get With The Guidelines ${ }^{\circledR}$ - Heart Failure. Retrieved from http://www.heart.org/idc/groups/heartpublic/@wcm/@private/@hcm/@gwtg/documents/downloadable/ucm_310967.pdf

Berkowitz, R., Blank, L., \& Powell S. K. (2005). Strategies to reduce hospitalization in the management of heart failure. Lippincott's Case Management, 10 (6 Supplement), S1-S15.

CDC Centers for Disease Control and Prevention. 2006. HF Fact Sheet Atlanta, GA: CDC. Retrieved November11, 2009, from http://www.cdc.gov/dhdsp/library/fs_heart_failure.htm

CDC Centers for Disease Control and Prevention. (2007). Kentucky HF fact sheet. Atlanta, GA: CDC. Retrieved from http://chfs.ky.gov/NR/rdonlyres/35BE13CC-ADB4-4ED0-945D73FBB626C82F/0/KyHeartFailureFactSheet_Oct2007.pd

Centers for Disease Control and Prevention. (2013). Interactive Atlas of Heart Disease and Stroke Tables. Retrieved from http://apps.nccd.cdc.gov/DHDSPAtlas/reports.aspx

Clark, R., Inglis, S., McAsister, F., Cleland, J., \& Stewart, S. (2007). Telemonitoring or structured telephone support programmes for patients with chronic heart failure: systematic review and meta-analysis. British Medical Journal. doi:10.1136/bmj.39156.536968.55

Ferrante, D., Sergio, V., Macchia, A., Soifer, S., Badra, R., Nul, D. ... Doval, H. (2010). Longterm results after a telephone intervention in chronic heart failure: DIAL (randomized trial of phone intervention in chronic heart failure) follow-up. Journal of the American College of Cardiology, 56, 372-378. doi:10.1016/j.jacc.2010.03.049 
Friedmann, E., Thomas, S., Fang, L, Morton, P., Chapa, D., \& Gottlieb, S. (2006). Depression, anxiety, and social isolation and chronic heart failure: American Heart Journal, 152 (5), 940. E1-8.

GESICA Investigators. (2005). Randomised trial of telephone intervention in chronic heart failure: DIAL trial. British Medical Journal, 331:425. doi: 0.1136/bmj.38516.398067.E0

Grancelli, H., Varini, S., Ferrante, D., Schwartzman, Sambrano, C., Soifer, S., ... Doval, H. (2003). Randomized trial of telephone intervention in chronic heart failure DIAL): study design and preliminary observations. Journal of cardiac failure, 9(3), 172-179.

Hunt, S. A., Abraham, W. T., Chin, M. H., Feldman, A. M., Francis, G. S., Ganiats, T. G., et al. (2005). ACC/AHA 2005 Guideline Update for the Diagnosis and Management of Chronic Heart Failure in the Adult: A Report of the American College of Cardiology/American Heart Association Task Force on Practice Guidelines (Writing Committee to Update the 2001 Guidelines for the Evaluation and Management of Heart Failure): Developed in Collaboration With the American College of Chest Physicians and the International Society for Heart and Lung Transplantation: Endorsed by the Heart Rhythm Society. Circulation, 112(12), e154-235.

Huttlinger, K., \& Purnell, L. D. (2008). People of Appalachian Heritage. Transcultural health care: a culturally competent approach $\left(3^{\text {rd }}\right.$ Ed) (pp. 95-112). Publisher: F.A.Davis Inglis, S., Clark, R., McAlister, F., Ball, J., Lewinter, C., Cullington, D., Stewart, S., \& Cleland, J. (2010). Structured telephone support or telemonitoring programmes for patients with chronic heart failure. Cochrane Database of Systematic Reviews, 8 ,

Jessup M., Abraham W., Casey D., Feldman, A., Francis G.,Ganiats T., ... Yancy, C. writing on behalf of the 2005 Guideline Update for the Diagnosis and Management of Chronic 
heart failure in the Adult Writing Committee. 2009 focused update: ACCF/AHA guidelines for the diagnosis and management of heart failure in adults: a report of the American College of Cardiology/American Heart Association Task Force on Practice Guidelines. Journal of the American College of Cardiology, 53, 1343- 82.

Kentucky Workforce Statistics. 2010. Retrieved from: http://www.workforcekentucky.ky.gov/article.asp?PAGEID=4\&SUBID $=\&$ articleID $=105$ 5

Klersy, C., Silvestri, A., Gabutti, G., Regoli, F., \& Auricchio, A. (2009). A meta-analysis of remote monitoring of heart failure patients. Journal of the American College of Cardiology, 54, 1683-1694. doi:10.1016/j.jacc.2009.08.017

Krumholz, H., Merrill, A., Schone, E., Schreiner, G., Chen, J., Bradley, E., ...Drye, E. (2009). Patterns of hospital performance in acute myocardial infarction and heart failure 30-day mortality and readmission. Circulation Cardiovascular Quality and Outcomes, 2, 407413. doi:10.1161/CIRCOUTCOMES.109.883256

Olatz, G., Ferrer, M., Point, A., Rue, M., Kotzeva, K., Wiklund, I., ...Alonso, J. (2009) Diseasespecific health-related quality of life questionnaires for heart failure: a systematic review with meta-analyses. Quality of Life Research, 18, 71-85. doi: 10.1007/s11136-008$9416-4$

Patient Protection and Affordable Care Act of 2010, Pub. L. No. 111-148, 124 Stat. 119 (2010, March 23).

Radzyminski, S. (2007). The concept of population health within the nursing profession. Journal of Professional Nursing, 23, 37-46. doi; 10.1016/j.profnurs.2006.10.004

Rector, T., \& Cohn, J. (2005). Minnesota Living with Heart Failure Questionnaire. Retrieved February 03, 2010, from www.mlhfq.org 
Riegel, B. (2009). SCHFI V 6.2. Retrieved from http://www.selfcareofheartfailureindex.com/?page_id $=6$

Riegel, B. 2008. Foreword: Self-care of heart failure: What is the state of the science? Journal of Cardiovascular Nursing, 23(3), 187-189.

Riegel, B., Carlson, B., Kopp, Z., LePetri, B., Glaser, D., \& Unger, A. (2002). Effect of a standardized nurse case-management telephone intervention on resource use in patients with chronic heart failure. Archives of Internal Medicine, 162, 705-712.

Riegel, B., Carlson, B., Moser, D., Sebern, M., Hicks, F., \& Roland, V. (2004). Psychometric testing of the self-care of heart failure index. Journal of cardiac failure, 10(4): 350-360.

Riegel, B., \& Dickson, V. (2008). A situation-specific theory of heart failure self-care. Journal of Cardiovascular Nursing, 23(3), 190-196.

Riegel, B., \& Dickson, V. (2010). Health and illness transition. In A. Meleis (Ed.), Transitions theory: Middle-range and situation-specific theories in nursing research and practice (pp. 320-325). New York: Springer.

Riegel, B, Jaarsma, T, \& Stromberg, A. (2012). A middle-range theory of self-care of chronic illnesss. Advances in Nursing Science, 35(3), 194-204.

Reigel, B., Lee, C., Dickson,V., \& Carlson, B. (2009). An update on the self-care of heart failure Index. Journal of Cardiovascular Nursing, 24 (6), 485-497.

Roger, V. L., Go, A. S., Lloyd-Jones, D. M., Benjamin, E. J., Berry, J. D., Borden, W. B., Bravata, D. M., ... Turner, M. B. (2012). Heart disease and stroke statistics—2012 update: a report from the American Heart Association. Circulation. 2012; 125(1):e2220. doi: $10.1161 /$ CIR.0b013e31823ac046 
Rugg, S. S., Bailey, A., \& Browning, S. R. (2008). Preventing cardiovascular disease in Kentucky: epidemiology, trends, and strategies for the future. Journal of the Kentucky Medical Association, 106, 149-161.

Scottish Intercollegiate Guidelines Network (2007). Critical appraisal: Notes and checklists. Retrieved September, 2007, from http://www.sign.ac.uk/methodology/checklists.html

Spielberger, C., Gorsuch, R., Lushene, R., Vagg, P, \& Jacobs, G. (1983) State-Trait Anxiety Inventory for Adults sampler set: manual, instrument, and scoring guide. Palo Alto: Mind Garden, Inc.

Telephone follow-up form. (n.d.) Retrieved December 8, 2011 from Amercian Heart Associaton website, http://www.heart.org/idc/groups/heartpublic/@wcm/@private/@hcm/@gwtg/documents/downloadable/ucm_428836.pdf

The AGREE Collaboration. The Appraisal of Guidelines for Research \& Evaluation (AGREE) Instrument, 2001. London: The AGREE Research Trust.

United States Centus Bureau. (2010). Retrieved from: http://quickfacts.census.gov/qfd/states/21000.html

United States Department of Agriculture. (2011). Retrieved from: http://www.ers.usda.gov/Statefacts/KY.HTM

United States Department of Health and Human Services, Agency for Healthcare Research and Quality. (2007). Guide to Prevention Quality Indicators: Hospital Admissions for Ambulatory Care Sensitive Conditions. Retrieved from http://www.qualityindicators.ahrq.gov/downloads/pqi/pqi_guide_v31.pdf

Volz, A., Schmid, J.-P., Zwahlen, M., Kohls, S., Saner, H., \& Barth, J. (2011). Predictors of readmission and health related quality of life in patients with chronic heart failure: a 
comparison of different psychosocial aspects. Journal of Behavioral Medicine, 34, 1322.

Wakefield, B., Holman, J., Ray, A., Scherubel, M., Burns, T., Kienzle, M., \& Rosenthal, G. (2009). Outcomes of a home telehealth intervention for patients with heart failure.

Journal of Telemedicine and Telecare, 15, 46-50. doi:10.1258/jtt.2008.080701 
Table 1

All Cause 30-Day Readmission

\begin{tabular}{lllllllllll}
\hline $\begin{array}{l}\text { Reason for } \\
\text { Readmit }\end{array}$ & $\begin{array}{l}\text { Pre } \\
\text { QOL }\end{array}$ & $\begin{array}{l}\text { Post } \\
\text { QOL }\end{array}$ & $\begin{array}{l}\text { Pre } \\
\text { Maint }\end{array}$ & $\begin{array}{l}\text { Post } \\
\text { Maint }\end{array}$ & $\begin{array}{l}\text { Pre } \\
\text { Mgt }\end{array}$ & $\begin{array}{l}\text { Post } \\
\text { Mgt }\end{array}$ & $\begin{array}{l}\text { Pre } \\
\text { Conf }\end{array}$ & $\begin{array}{l}\text { Post } \\
\text { Conf }\end{array}$ & $\begin{array}{l}\text { Pre } \\
\text { Anx }\end{array}$ & $\begin{array}{l}\text { Post } \\
\text { Anx }\end{array}$ \\
\hline Numbness & 58 & 52 & 46.662 & 53.328 & 40 & 50 & 44.48 & 50.04 & 49 & 42 \\
HF & 50 & 51 & 43.329 & 56.661 & 35 & 45 & 44.48 & 44.48 & 71 & 69 \\
URI & 51 & 44 & 73.326 & 76.659 & 70 & 75 & 100 & 100 & 33 & 32 \\
HF & 44 & 43 & 59.994 & 63.327 & 75 & 80 & 72.28 & 72.28 & 39 & 35 \\
Cath & 58 & 51 & 39.996 & 59.994 & 30 & 75 & 66.72 & 66.72 & 38 & 40 \\
CP & 57 & 55 & 53.328 & 59.994 & 35 & 40 & 33.36 & 44.48 & 38 & 37 \\
HF & 44 & 43 & 69.993 & 73.326 & 60 & 60 & 66.72 & 66.72 & 38 & 33 \\
\hline
\end{tabular}

URI = Upper respiratory infection

Cath $=$ Cardiac catheterization

$\mathrm{CP}=$ Chest pain

Maint $=$ SCHFI A - Self-care maintenance

$\mathrm{Mgt}=\mathrm{SCHFI} \mathrm{B}-$ Self-care management

Conf $=$ SCHFI C - Self-care confidence

Anx $=$ S-Anxiety subscale of the STAI 


\title{
Appendix A
}

\section{KENTUCKY \\ INSTITUTE}

\author{
October 12, 2011
}

Debra Cummings, APRN

5000 KY RT 321, Suite 4102

Prestonsburg, KY 41653

Dr. Ms. Cummings;

Please accept this letter as permission to utilize Kentucky Heart Institute, Inc. patients to participate in your capstone project. I understand that your project relates to better management of our heart failure population: "The Effectiveness of a Structured Telephone Support Program for Rural Patients with Heart Failure". Please let me know if I can be of further assistance and hopefully you could share your outcomes.

Sincerely

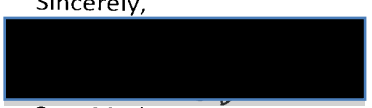

Sara Marks

Vice President 